\title{
As Narrativas de Duas Professoras em seus Processos de Desenvolvimento Profissional em Educação Estatística*
}

\author{
The Narratives of Two Teachers in their Professional Development \\ Processes in Statistics Education
}

Celi Espasandin Lopes ${ }^{* *}$

\begin{abstract}
Resumo
Este artigo discute a potencialidade das narrativas para o desenvolvimento profissional de duas professoras que ensinam Matemática no Ensino Fundamental e estão inseridas em um grupo de trabalho colaborativo denominado Grupo de Investigação e Formação em Educação Matemática (GIFEM), o qual tem por objetivo viabilizar aos professores participantes a superação do desafio de implementar a Educação Estatística em suas aulas. Considera-se, neste estudo, o desenvolvimento profissional como um processo que salienta os aspectos que o professor, em função de suas competências, pode desenvolver e discute as contribuições da produção de narrativas para esse processo. Analisa as narrativas escritas e orais das professoras, produzidas a partir de atividades desenvolvidas com turmas do $5^{\circ}$ e do $9^{\circ}$ anos e busca evidências da ampliação do conhecimento profissional das professoras, do redimensionamento de sua prática e da produção de saberes que foram socializados durante os encontros do GIFEM.
\end{abstract}

Palavras-chave: Desenvolvimento Profissional. Narrativas. Prática Docente. Educação Estatística. Educação Matemática.

\begin{abstract}
In this article the power of narratives used during the professional development of two mathematics teachers, who teach in the elementary grades, is discussed. The teachers were participants in a collaborative study group GIFEM (Group for Investigations and Professional Development in Mathematics Education). The objectives of the group included the support of participating teachers to overcome the challenge of implementing Statistics Education in their classes. In the work of the group, the professional development involves the production and sharing of narratives as a process that builds on teachers' strengths in order to enhance their practices. The contributions to professional growth of the narratives produced by the teacher participants are discussed. Written and oral narratives produced by the two participating teachers describe and analyze the activities they developed and implemented in their 5th and 9th grade classrooms. These narratives were analyzed by the author in search for evidence of enhanced professional knowledge, new dimensions incorporated into professional practices, and the production of knowledge occurring as reflections were shared during the meetings of GIFEM.
\end{abstract}

"Projeto de pesquisa financiado pelo Conselho Conselho Nacional de Desenvolvimento Científico e Tecnológico (CNPq).

"Professora Titular do Programa de Pós-Graduação em Ensino de Ciências e Matemática da Universidade Cruzeiro do Sul (UNICSUL). Endereço para correspondência: Av. Gessy Lever, 915/383, CEP: 13272-000. Valinhos, SP, Brasil.E-mail: celilopes@uol.com.br. 
Keywords: Professional Development. Narratives. Teaching Practice. StatisticsEducation. MathematicsEducation.

\section{Introdução}

O estudo aqui apresentado decorre de um projeto de desenvolvimento profissional de professores em Educação Estatística, o qual gerou um Grupo de Investigação e Formação em Educação Matemática (GIFEM), que tem por princípio um trabalho de cooperação entre duas pesquisadoras e cinco professores que ensinam Matemática no Ensino Fundamental e visa a produção de novos saberes para todos eles. Discutiremos as narrativas das experiências com Educação Estatística de duas das professoras participantes - identificadas aqui por Adr e Sez - no contexto desse grupo.

Acreditamos que o uso das narrativas orais e escritas pode contribuir positivamente para o contexto de onde emergiram e ampliar o conhecimento profissional dos professores, tornando o espaço formativo mais adequado para o desenvolvimento docente.

Diante disso, optamos por considerar o problema central: quais as contribuições das narrativas ao processo de desenvolvimento profissional em Educação Estatística de duas professoras? Com base nele, delineamos duas questões a serem investigadas:

1) Que conhecimentos são revelados pela escrita das professoras a respeito da Matemática e da Estatística?

2) Como a produção de narrativas escritas e orais contribuiu para o desenvolvimento profissional das professoras?

$\mathrm{Na}$ busca de respostas a estas questões, analisamos as narrativas produzidas pelas professoras, partindo do princípio de que, ao produzi-las, o professor não só aprende porque organiza suas ideias e sistematiza suas experiências, atribuindo significados à elas mas também ensina, pois, ao compartilhar essas experiências, possibilita ao outro (leitor) ressignificar seus próprios saberes e experiências (FREITAS; FIORENTINI, 2007).

Quando imersos em um processo de desenvolvimento profissional, os professores têm a expectativa de ampliar seu conhecimento didático - no caso deste trabalho, sobre os conteúdos matemáticos e estatísticos. Ao visarmos essa ampliação, cabe considerar a complexidade da atividade docente e pautar propostas de formação que possibilitem ao professor refletir sobre a teoria e a prática a partir da análise de suas experiências. Para tanto, passaremos à discussão sobre as diretrizes teóricas decorrentes da produção científica em Educação Estatística. 


\section{Educação Estatística}

A complexidade da sociedade contemporânea obrigou-nos a quantificar muita informação, exigindo que a escola promova uma formação que vá além de ensinar conteúdos matemáticos e estatísticos e desenvolva, nos estudantes, capacidades em diferentes formas de raciocínio, para que adquiram autonomia para selecionar as informações que os auxiliem na resolução de um problema e/ou na tomada de decisão.

A Matemática contribui para a compreensão dos fenômenos científicos e sociais que decorrem dos movimentos gerados pelas ações humanas. A Estatística, com seus conceitos e métodos para coletar, organizar e analisar informações diversas, tem-se revelado um poderoso aliado nesse desafio que é transformar a informação bruta em dados que permitam ler e compreender uma realidade. E, talvez por isso, tenha se tornado uma presença constante no dia a dia de qualquer cidadão, fazendo com que haja um amplo consenso em torno da ideia segundo a qual a literacia estatística ${ }^{1}$ deve ser uma prioridade da sociedade moderna, marcada por uma cidadania com responsabilidade social. Mas, para isso, é preciso entender e ser capaz de produzir argumentos quantitativos. Dessa forma, coletar, organizar e representar a informação são atividades da maior importância no mundo atual.

Para saber decodificar essa informação, é necessário possuir um pensamento estatístico, ou seja, "ser capaz de utilizar ideias estatísticas e atribuir um significado à informação estatística. Por outras palavras, ser capaz de fazer interpretações com base em conjuntos de dados, representações de dados ou mesmo com um resumo dos dados" (GARFIELD; GAL, 1999, p. 207). O desenvolvimento dessa forma de pensar está atrelado às várias formas de raciocinar matematicamente, em particular, no que se refere ao raciocínio probabilístico.

A Probabilidade é um tema matemático essencial ao fazer estatístico. Uma análise de dados não se realiza sem a mobilização do raciocínio probabilístico, o qual nos permite medir a chance e analisar as possibilidades de um evento ocorrer ou não. Mas, para o estudo da Estatística, não é suficiente apenas saber realizar o cálculo de probabilidade, é preciso mobilizar essa forma de pensar sobre o aleatório, para ser capaz de estabelecer relações entre os dados estatísticos, o que gera o imbricamento entre a Matemática e a Estatística.

\footnotetext{
${ }^{1}$ Entende-se Literacia Estatística como a capacidade para interpretar argumentos estatísticos, superando as competências computacionais e permitindo que, por meio de análises fundamentadas, se possa tomar decisões.
} 
Assim, a Educação Estatística emerge desse entrelaçamento, o qual permite uma compreensão do porquê e da forma como são conduzidas investigações estatísticas. Isso inclui reconhecer e compreender todo o processo investigativo - a elaboração da pergunta, a escolha dos instrumentos para coleta de dados, sua análise e a escolha de pressupostos de testes, etc. - ; entender como os modelos são usados para simular fenômenos aleatórios e como os dados são produzidos para estimar as probabilidades; e ser capaz de compreender e utilizar o contexto de um problema para planejar e avaliar as investigações e para tirar conclusões (LOPES, 2008).

No cotidiano, muitas decisões sobre as quais as pessoas são chamadas a pronunciarem-se envolvem riscos e nem todos os dados estão completos ou são conhecidos. Dessa forma, é importante que se promova uma educação na qual os indivíduos aprendam a avaliar o risco de situações tão variadas como as sociais, as políticas, as econômicas, as científicas, as tecnológicas ou qualquer outra combinação, e, simultaneamente, possam encontrar o equilíbrio entre o que pode ser uma situação desse tipo e os benefícios que dela se podem retirar.

Diante disso, as pesquisas em Educação Estatística têm destacado a necessidade de investimentos na formação inicial e contínua dos professores (LOPES, 2003). Especificamente no que se refere à Estatística, Pfannkuch e Ben-Zvi (2011) defendem que, em cursos de formação de professores nessa área, é importante desenvolver a apreciação para o valor do discurso e da argumentação.

A formação inicial e contínua dos professores que ensinam Matemática na Educação Básica não tem preparado esses profissionais para o domínio teórico-metodológico da Educação Estatística e de muitos outros campos da Educação Matemática.

Assim, o GIFEM se originou tanto da necessidade de promover investigações sobre o desenvolvimento profissional desses professores em temas relacionados à Probabilidade e à Estatística, como da necessidade que alguns desses professores têm de efetivar a Educação Estatística em suas aulas.

Neste artigo, trazemos a discussão sobre as narrativas escritas e orais da professora Adr e da professora Sez. Para isso, evidenciaremos a seguir a potencialidade das narrativas, no desenvolvimento profissional do professor. 
30 papel das narrativas no desenvolvimento profissional do professor que ensina Matemática

Neste estudo, centramos o foco sobre o potencial das narrativas no desenvolvimento profissional do professor que ensina Matemática no Ensino Fundamental, entendendo o desenvolvimento profissional como uma opção do professor, em que ele busca um diálogo entre o estudo teórico e sua prática, o que gera um movimento que lhe permite a percepção de suas competências e fragilidades, podendo trabalhar sobre elas. Desenvolve, então, certo autodidatismo, em que ele procura, decide, projeta e executa um plano de formação. É nessa busca que aprimora seus conhecimentos, desenvolve seus talentos e redimensiona as suas atitudes (LOPES, 2003).

A construção de narrativas e a leitura destas, em contextos de formação inicial e contínua, permitem discussões e análises que levam ao desenvolvimento pessoal e profissional dos professores.

De acordo com Reis (2008), quando os professores contam suas histórias sobre algum acontecimento de suas aulas, fazem algo mais do que registrar essa situação: alteram formas de pensar e de agir, sentem-se motivados para modificar as suas práticas e manter uma atitude crítica e reflexiva sobre o seu desempenho profissional.

O desenvolvimento profissional dos professores vincula-se à ampliação de seu conhecimento profissional. Eles precisam possuir conhecimentos sobre a matéria que ensinam; conhecer o conteúdo em profundidade, sendo capazes de organizá-lo mentalmente, de forma a estabelecer inúmeras inter-relações; relacionar esse conteúdo ao ensino e à aprendizagem, em um processo de interação com os alunos, considerando o desenvolvimento cognitivo destes; e, também, compreender o contexto, tendo clareza do local em que ensinam e a quem ensinam.

O elemento central do conhecimento profissional do professor é, sem dúvida, o conhecimento didático do conteúdo, porém não é o suficiente. Faz-se necessária “a combinação adequada entre o conhecimento da matéria a ensinar e o conhecimento pedagógico e didático de como ensinar" (MARCELO GARCÍA, 1999, p. 88).

O conhecimento didático do conteúdo é uma síntese dos conteúdos a ensinar com os modos de fazê-lo, incluindo formas de representação das ideias, analogias importantes, ilustrações e exemplos próximos ao contexto. Está incorporada a esse conhecimento a habilidade de representar e formular o conteúdo conceitual e/ou procedimental, torná-lo 
compreensível aos alunos e entender o que torna mais, ou menos, difícil a aprendizagem de um conceito.

Esse conhecimento didático do conteúdo amplia-se no movimento do professor, ao estudar, refletir e agir. Ao envolver-se em um processo de desenvolvimento profissional, o professor reflete sobre os textos teóricos que estuda, sempre considerando o seu fazer docente, e amplia esse processo reflexivo, ao se propor a narrar suas experiências. Dessa forma, ele aprende e ensina. Assim, a narrativa

[...] como processo de reflexão pedagógica permite ao professor, à medida que conta uma determinada situação, compreender causas e conseqüências de atuação, criar novas estratégias num processo de reflexão, investigação e nova reflexão. A narrativa é também um processo de interação com o outro, e nessa medida ajuda-nos a compreender qual o papel de cada um de nós na vida dos outros. A interação com um grupo de pessoas ao longo de vários anos, proporciona ao investigador um maior conhecimento de si próprio, pela reflexão sobre o efeito que as suas atitudes provocam nos outros, ao mesmo tempo em que obriga a equacionar aprendizagens, a reconhecer limites pessoais e a redefinir modos de agir. (GALVÃO, 2005, p. 343).

Então, as narrativas se tornam essenciais na elaboração e na reelaboração do conhecimento profissional do professor. Leal (2009, p. 12) considera que "narrar nosso fazer educativo implica em conjugar os verbos na forma reflexiva: vermo-nos, pensarmo-nos, questionarmo-nos, duvidarmos de nossas palavras". O conhecimento profissional dos professores não é construído de forma linear, ele emerge em meio à complexidade do seu fazer docente, em salas de aulas marcadas pela diversidade. Assim, ele é produzido como uma teia, entrelaçado por relações estabelecidas a partir de conflitos e interações, repleto de significados pessoais e sistematizado em sua silenciosa reflexão. Dessa forma, a narrativa escrita pode ser concebida como um instrumento que estrutura o movimento da reflexão, que o ato de escrever instaura (PÉREZ, 2006).

Neste estudo, buscamos, durante os encontros do GIFEM, um trabalho de colaboração pautado no debate sobre as reflexões das distintas práticas, a fim de aprofundar e redimensionar os saberes e os fazeres docentes. Nesse espaço formativo, o professor é o elemento-chave na criação do ambiente da sala de aula: cabe a ele a responsabilidade de propor e organizar tarefas, bem como de coordenar o desenvolvimento das atividades de ensino com os alunos.

Portanto, a narrativa escrita assume, no movimento do GIFEM, o papel duplo de sistematizar e socializar o conhecimento profissional construído em relação à Educação Estatística. Entendemos que

[...] o conhecimento da compreensão do que é o ensino pode ser feito a partir da reconstrução dos acontecimentos pelos professores, numa situação de partilha das suas histórias. Isto se baseia nas premissas de que ensinar é experienciado como 
acontecimentos sociais complexos, que o conhecimento está organizado em teorias explicativas e, por sua vez, serve de lente interpretativa da compreensão da experiência de cada um (GALVÃO, 2005, p. 330).

Isso remete a pensar a narrativa como processo de formação no qual se evidencia a relação entre investigação e formação, colocando em confronto saberes diferenciados, provenientes de modos de vida que refletem distintas aprendizagens. O processo de narrar suas experiências possibilita ao professor oportunidades de reflexão e de sistematização dessa reflexão, à medida que ele se confronta com aspectos significativos do processo de ensino e aprendizagem.

Percebemos que as narrativas orais e escritas socializadas no GIFEM nos permitem observar a ampliação do conhecimento profissional de cada docente e compreender que esse processo é lento e complexo, mas gera um desenvolvimento profissional significativo. Assumimos, portanto, neste grupo de pesquisa, que o professor é um elemento fundamental, pois o seu saber e o seu saber fazer são significativos e essenciais para a criação de novas perspectivas teóricas e metodológicas.

Nos encontros do GIFEM, as discussões consideram que as "experiências em sala de aula e em ambiente de pesquisa podem ilustrar o potencial da narrativa para o ensino e a aprendizagem da Matemática" (FREITAS; FIORENTINI, 2007, p. 65). Assim, ao propormos um trabalho com narrativas escritas, como possibilidade de reflexão sobre a prática docente, tomamos o cuidado de que elas não fossem meras exposições e descrições de fatos ocorridos, nem tampouco se constituíssem em uma relação de experiências de vida, sem conexão e problematização. "Há que se ter clareza do porquê, de quando e como usar os diferentes recursos formativos, estando atento para não simplificar a complexidade presente nas narrativas" (SANTOS, 2008, p. 216).

Para discutirmos as narrativas de Adr e Sez, vamos, primeiramente, contar um pouco sobre cada uma.

\section{As professoras Adr e Sez}

Adr é professora de Matemática efetiva desde 2002 na Secretaria Municipal de Educação de Valinhos (SME/Valinhos), cidade do interior de São Paulo, e esteve constantemente inserida em grupos de estudos e pesquisas e em processos de formação contínua. Ela sempre lecionou para os anos finais do Ensino Fundamental e, atualmente, além 
de lecionar, trabalha com a coordenação da área de Matemática no Departamento Pedagógico da SME/Valinhos.

Sua jornada de trabalho é de 44 horas, das quais 24 são dedicadas a lecionar e 20 são para a orientação pedagógica. Ela frequenta o Grupo de Sábado (GdS), da Faculdade de Educação (FE) da UNICAMP, o Grupo de Estudos e Pesquisas em Educação Matemática para os Anos Iniciais (GEPEMAI), também da FE/UNICAMP, e é membro fundador do Grupo de Investigação e Formação em Educação Matemática (GIFEM), no qual se desenvolve a pesquisa aqui apresentada. Em todos esses grupos, sua participação é voluntária, e ela expressa ter por objetivo o seu desenvolvimento profissional.

Adr já cursou três especializações em Ensino de Matemática no LEM/IMECC/UNICAMP, especialização em Prática Pedagógica em Matemática na FE/UNICAMP e tornou-se Mestre em Educação pela FE/UNICAMP.

Durante os encontros, tem participação ativa, manifestando explicitamente suas potencialidades, ansiedades, dúvidas, crenças e perspectivas como professora. Seu histórico de formação evidencia que se trata de uma profissional que investe continuamente em seu desenvolvimento profissional e foi ela quem auxiliou a pesquisadora e autora deste texto a captar colegas professores que tivessem o desejo de compor um grupo de investigação e formação. Nasceu assim o Grupo de Investigação e Formação em Educação Matemática (GIFEM), em abril de 2012, inicialmente com uma pesquisadora e três professores.

Sez é graduada em Pedagogia, atua como docente há sete anos e exerceu a função de coordenadora pedagógica por um ano e meio. Atualmente, é professora dos anos iniciais do Ensino Fundamental e ensina Matemática para uma turma de $5^{\circ}$ Ano. É efetiva desde 2012 na Secretaria Municipal de Educação de Campinas (SME/Campinas), cidade do interior de São Paulo, com jornada de trabalho de 32 horas semanais.

Ela frequenta o Grupo de Estudos e Pesquisas em Educação Matemática para os Anos Iniciais (GEPEMAI), da FE/UNICAMP, e o Grupo de Investigação e Formação em Educação Matemática (GIFEM), na SME/Valinhos. Nos dois grupos, sua participação também é voluntária e, segundo ela, tem por objetivo melhorar sua prática e ampliar as possibilidades de aprendizagens das crianças.

Os cursos de formação continuada que frequentou foram sobre a Arte na Matemática e Geometria. Ela estudou Probabilidade no Ensino Médio e teve a disciplina de Estatística em sua formação inicial com uma abordagem centrada em cálculos. Ela nunca utilizou recursos tecnológicos no estudo de Probabilidade e/ou Estatística. 
Em suas aulas de Matemática, sempre buscou trabalhar com a resolução de problemas e valorizar a diversidade de procedimentos apresentados pelos alunos.

A participação de Sez no grupo tem sido importante, pois ela tem uma postura participativa e gosta de narrar oralmente suas experiências, compartilhando suas reflexões sobre elas. Sempre explicita suas dúvidas e a forma como encaminha os desafios surgidos em suas aulas.

As atividades descritas a seguir foram expostas pelas professoras em suas narrativas o texto de Adr foi o segundo produzido desde o início do GIFEM e o de Sez foi o primeiro.

\section{As narrativas de Adr e de Sez}

Em nossa discussão sobre as narrativas elaboradas por Adr e Sez, consideramos que, no processo de narrar,

[...] incluem-se cinco níveis de representação (RIESSMAN, 1993) da experiência vivida: dar sentido, contar, transcrever, analisar e ler. E poder-se-ia, ainda, acrescentar interpretar, uma vez que quem lê, necessariamente, dá um novo sentido ao texto, de acordo com as suas vivências e referências. Cada um destes níveis é, ao mesmo tempo, reducionista e expansionista. Os narradores escolhem partes significativas do todo, mas acrescentam-lhes outros elementos interpretativos (GALVÃO, 2005, p. 332-333).

As narrativas de Adr e Sez ainda não contemplam todos os níveis considerados, pois essa prática no grupo ainda é incipiente.

Adr relata que propôs aos alunos do $9^{\circ}$ ano a ideia de desenvolverem um projeto de investigação estatística, durante o ano letivo de 2013. Ao iniciarem as discussões sobre o tema a ser investigado, a professora sugeriu que o tema fosse atletismo, pois percebeu que, durante a discussão com a turma, eles desconheciam várias modalidades a serem disputadas nas Olímpiadas. Orientou os alunos, inicialmente, para consultar na internet o que significava atletismo e quais as modalidades existentes. A consulta deveria ser registrada por escrito. Após dividir a turma em grupos, cada um deles escolheu uma determinada modalidade para aprofundar o conhecimento sobre ela.

Adr revela, em sua narrativa, que as discussões realizadas no GIFEM sobre o fato de um processo de investigação estatística considerar dados reais, que devem ser coletados, organizados e representados pelos alunos, levou-a a elaborar uma proposta na qual eles deveriam realizar algumas medições na quadra para a realização de corrida, arremesso, salto em altura e salto em distância. Também teriam que elaborar uma ficha para registrar os dados 
pessoais de cada aluno participante de determinada modalidade - nome, peso, altura, idade, sexo e ano de nascimento.

O projeto, nos conta Adr, foi desenvolvido em seis etapas: investigação sobre o tema; preparação da ficha de registro; coleta dos dados; tabulação dos dados; representação gráfica dos dados; elaboração de relatório sobre a análise dos dados; e apresentação do projeto à comunidade escolar.

Nesta atividade Adr trabalhou com índices percentuais, registro de dados que envolviam movimento aleatório, elaboração de ficha de registro, cálculo e interpretação de medidas de posição, construção e leitura de tabelas e gráficos e comparação de valores numéricos. Além disso, os alunos exploraram o uso da internet e da planilha eletrônica (Excel), aprimorando o domínio de procedimentos relacionados ao uso do computador.

Segundo Adr, o envolvimento dos alunos foi significativo, pois eles se apropriaram dos conteúdos abordados e desenvolveram habilidades importantes em uma investigação estatística, particularmente no que se refere à argumentação numérica. Além disso, mobilizaram competências de leitura e escrita para redigir o relatório final, elaborar os cartazes e comunicar oralmente o desenvolvimento e os resultados do projeto.

Esta narrativa evidencia a atenção que Adr teve ao trabalhar o processo investigativo, considerando, inicialmente, os componentes de formulação de questões e coleta de dados. Para que esse desenvolvimento seja possível, é necessário que o professor promova a todo momento a problematização por parte do aluno. A atividade descrita na narrativa da professora Adr revela sua criatividade e perspicácia ao pensar um projeto sobre atletismo e evidencia, também, que ela tem ampliado sua sensibilidade para visualizar a utilização manipulativa da informação estatística e se preocupa em mobilizar os alunos para problematizações constantes.

Adr, em sua narrativa (maio, 2013), destaca a importância de sua postura ao ouvir o aluno.

Essa experiência foi bastante interessante pelo envolvimento que proporcionou nos alunos... aprendi como é importante dar espaço aos alunos para colocarem suas ideias, defenderem suas opiniões, desenvolvendo assim seu poder de argumentação na tomada de decisões baseadas em dados pesquisados.

Na sua narrativa de aula, Adr indica a ampliação de seu conhecimento profissional, no que se refere ao ensino da Estatística, e enfatiza a importância do grupo GIFEM nesse processo. Ela evidencia a necessidade de estimular, nos alunos, habilidades de argumentação 
e oralidade para promover o desenvolvimento do pensamento estatístico. Assim, o ato de narrar a história de sua aula torna-se, de fato, um ato de conhecimento (PÉREZ, 2006).

Adr ampliou seu conhecimento profissional, assim como ocorreu com Sez, e ambas construíram seus projetos - dos quais resultaram estas narrativas - a partir da realidade vivida por seus alunos. Por essa razão, desenvolveram temas diferentes.

Sez relata que preparou um projeto sobre brincadeiras e iniciou o trabalho questionando as crianças sobre com o que ou do que costumavam brincar. Ela registrou na lousa as brincadeiras indicadas pelas crianças. Finalizado esse registro, as crianças deveriam votar em uma brincadeira. $\mathrm{O}$ voto seria marcado com um quadradinho colorido a ser colocado no gráfico de barras traçado na lousa.

A professora destaca que as crianças não tinham familiaridade com a construção de gráficos, e essa tarefa não foi simples para elas. Como o projeto elaborado por Sez tinha a intenção de envolver as outras turmas de quintos anos, pois eles iriam todos brincar na quadra da escola, ela propôs aos seus alunos que investigassem a brincadeira preferida dos colegas das outras turmas. As crianças se empolgaram e quiseram fazer mais perguntas, por isso, a professora trabalhou com elas a elaboração de um questionário que eles utilizariam para coletar os dados com seus colegas de outras turmas. Essa elaboração, segundo a professora, também não foi simples, pois as crianças precisaram ser provocadas o tempo todo a pensar que questões poderiam ser feitas sobre o assunto investigado.

Sez relata que já tinha experiência em trabalhar com projetos, no entanto, destaca que seu conhecimento matemático não foi suficiente para explorar mais a Matemática neste trabalho. O projeto das brincadeiras, desenvolvido com sua turma de $5^{\circ}$ ano, envolveu problematização; formulação de questões; coleta de dados; tabulação de dados; construção e leitura de gráficos; e comparação de dados. Houve uma aproximação com as ideias do fazer estatístico e a narrativa da professora revela sua habilidade em provocar as crianças para problematizar situações e argumentar sobre o que deseja defender.

Além dessa introdução estatística, expressa por Sez em sua narrativa escrita, sua narrativa oral para o grupo revela que essa atividade deu oportunidade para as crianças trabalharem com operações matemáticas básicas, proporcionalidade, espaço e formas e plano cartesiano. A narrativa escrita, porém, deixa claro que Sez não tem percepção da aprendizagem de todos esses conteúdos matemáticos, pois ela evidencia apenas a sua abordagem pedagógica, que viabilizou às crianças uma aproximação com o raciocínio 
combinatório e probabilístico, ao explorar as possibilidades de brincadeiras e analisar as chances de votos para cada uma delas.

Sez declara, em sua narrativa (junho, 2013):

Este projeto gerou a oportunidade para conversar com as crianças sobre democracia, sobre as votações que ocorrem nas urnas eletrônicas, que mesmo que não estejamos contentes com o resultado das eleições somos obrigados a acatar o que a maioria decidiu, e que de nada adianta reclamar.

Neste relato, Sez evidencia que sua abordagem não se limita apenas ao estudo da Matemática e da Estatística. Ao expressar seu talento em usar a Matemática para fazer a leitura de mundo, ela traz às discussões realizadas no GIFEM um outro foco a ser estudado e analisado: a perspectiva cultural e social do conhecimento matemático e estatístico.

Cada projeto realizado é um desafio, uma conquista em sua conclusão, enriquecedor para minha formação como professora e acredito que também para as crianças, que não aprendem somente conteúdos, mas posturas a serem adotadas em sociedade, $e$ principalmente, se formam cidadãos. Inserir estatística neste projeto só foi possível pelos estudos que tenho feito no grupo. (SEZ, narrativa, junho, 2013)

Ela destaca a importância da participação no grupo para a ampliação de seu conhecimento profissional em relação ao conhecimento estatístico e matemático e considera que, sem essa participação, não teria desenvolvido o projeto dessa forma.

Nos projetos desenvolvidos por Adr e Sez, destacam-se as diferenças entre o fazer matemático e o fazer estatístico, pois, enquanto muitos problemas surgem a partir da Matemática aplicada a contextos que é removido para revelar padrões matemáticos, na Estatística é necessário um olhar pontual sobre o contexto. Concluímos, então, que os estatísticos, assim como os matemáticos, analisam padrões, mas o significado dos padrões, na Estatística, depende do contexto.

É importante notar, ainda, que os projetos desenvolvidos por Adr e Sez têm características decorrentes das discussões realizadas nos encontros do GIFEM, quando se definiu que o estudo estatístico deve ocorrer centrado na resolução de problemas, com um processo investigativo que envolva quatro componentes: formular questões, coletar dados, analisar dados e interpretar resultados (FRANKLIN et al., 2007).

As narrativas de Adr e Sez revelam uma diferença em relação aos relatos de experiência, pois seus textos são "de natureza reflexiva e problematizadora de suas práticas docentes e de seus saberes experienciais" (FREITAS; FIORENTINI, 2007, p. 65).

As escritas e as leituras de relatos de experiências da prática docente requerem, por parte de quem escreve e de quem lê, um processo reflexivo que se traduz em ideias e palavras, 
revelando uma busca pela produção de saberes. Se formos capazes de produzir uma escrita que potencialize o que fazemos, fortaleceremos os saberes que engendramos, faremos novas descobertas e poderemos redimensionar nossas verdades; por fim, nos veremos com mais orgulho e dignidade e perceberemos o valor de ser professor (LEAL, 2009).

Embora as narrativas não tenham sido trazidas na íntegra neste texto, até porque serão publicadas pelas respectivas professoras posteriormente, destacamos que, nessas suas produções escritas, as professoras justificam o que as levou a desenvolver determinada atividade com seus alunos e deixam claras suas intenções pedagógicas (NACARATO; PASSEGGI, 2011).

As narrativas de Adr e Sez permitiram-nos perceber que o modo como organizam a aula e interagem com os alunos revela o construir e o reconstruir da história de suas experiências pessoais. A organização do discurso produzido pelas interações sociais em um espaço formativo, como o GIFEM, incide no próprio discurso e nas atividades elaboradas e socializadas.

Assim, a narrativa se constitui em um processo de interação, independentemente da forma como é utilizada. Ela permite que um interaja com o outro, próximo e distante; possibilita a interpretação de diferentes vozes; auxilia no redirecionamento de práticas, no repensar de intenções e objetivos e na criação de novas ações docentes. Através dessa interação, o professor conhece melhor a si e aos outros (REIS, 2008).

Escrever suas histórias de aulas possibilita ao professor se colocar como produtor de conhecimento, pois, ao descrever as ações de sua prática, evoca a memória do que foi marcante e corporifica o que julga essencial por meio da linguagem. Para além de uma leitura/releitura do vivido (PÉREZ, 2006), este exercício se caracteriza, do ponto de vista da formação, como um processo de apropriação de novos conhecimentos e como propulsor do desenvolvimento profissional.

A literatura tem tematizado e compreendido o trabalho com narrativas como uma estratégia promissora para cursos de formação de professores e para o desenvolvimento profissional, no sentido de integrar narrativa e abordagem reflexiva (SANTOS, 2008).

Em função da complexidade e da especificidade da prática docente, a abordagem reflexiva na formação inicial e continuada de professores tem chamado a atenção para o debate em torno de modelos de formação profissional considerados insuficientes para uma análise mais coerente dos processos de ensinar e aprender. Ensinar caracteriza-se como uma atividade complexa, contextual, imprevisível, permeada por conflitos que requerem 
posicionamentos políticos e éticos. Além disso, na dinamicidade da sua ação, o professor tem seu modo peculiar e idiossincrático de interpretar as situações e tomar decisões para resolver os problemas.

Essas características da profissão docente exigem que o professor esteja permanentemente envolvido em processos de desenvolvimento profissional e que estes sejam marcados pelo desencadeamento do processo reflexivo, o qual se (re)significa quando se utilizam as narrativas escritas, pois elas conduzem a um refletir que possibilita ao autor modificar a relação com seu próprio texto e (re)construir o sentido de sua experiência pessoal e profissional (PÉREZ, 2006).

O processo de desenvolvimento profissional, quando envolve a produção de narrativas, permite ao professor descrever seu percurso por meio de um discurso no qual revela a dinâmica das relações que ele estabelece com o saber, com o outro e consigo mesmo. Esse movimento marcado pela (re)construção e pela (re)apropriação do saber permite a ele, enquanto narrador, que se perceba como autor de seu desenvolvimento profissional.

Dessa forma, neste estudo, dar importância às narrativas das professoras permitiu preservar a identidade profissional, reconhecer e valorizar as professoras como produtoras de saberes (NACARATO; PASSEGGI, 2011).

\section{Algumas considerações}

As narrativas de Adr e Sez decorreram de um processo vivido no GIFEM, onde encontros têm ocorrido de maneira que se possibilite aos professores adquirir uma nova concepção sobre a Matemática e a Estatística, a partir da reflexão sobre a teoria e a prática e, particularmente, pelas narrativas orais e escritas produzidas por eles.

A busca pela implementação da Educação Estatística em suas aulas tem caracterizado um desenvolvimento profissional que emerge de processos reflexivos realizados nos encontros, com seus pares e nos momentos de docência. A todo momento, os professores revelam a produção de novos conhecimentos profissionais, colocando-se como protagonistas de suas aprendizagens e, por consequência, de seus próprios processos de desenvolvimento profissional.

Esse movimento tem gerado um aprimoramento didático em relação ao conhecimento matemático e estatístico. A leitura, a discussão e a análise das narrativas acerca das práticas e dos conhecimentos dos professores têm permitido aprofundar e desenvolver conhecimento 
sobre o ensino e a aprendizagem da Matemática e da Estatística. Assim, o processo de narrar experiências caracteriza-se como processo de formação e de elaboração de conhecimento profissional.

Os professores, quando contam histórias sobre algum acontecimento do seu percurso profissional, fazem algo mais do que registrar esse acontecimento; acabam por alterar formas de pensar e de agir, motivam-se para modificar as suas práticas e manteem uma atitude crítica e reflexiva sobre o seu desempenho profissional. Por meio da construção de narrativas, os professores reconstroem as suas próprias experiências de ensino e aprendizagem e os seus percursos de formação.

Como lembra Leal (2009, p. 11), "aprende quem conta, quem escuta, quem escreve, quem lê." Assim como a autora, defende-se que o professor resgate sua própria palavra, seu jeito único de dizer quem é, o que faz e como pensa seu fazer docente.

As narrativas produzidas pelas professoras neste estudo permitem revelar saberes construídos na prática da profissão, os quais se tornam essenciais à formação, pois são decorrentes de experiências marcadas pela complexidade presente na sala de aula. Entende-se, assim, que, ao produzir narrativas, essas professoras estão contribuindo para que sua categoria profissional seja de fato reconhecida como produtora de conhecimento.

Uma prática dialógica no espaço formativo, que visa ao desenvolvimento profissional de professores, assume um papel fundamental sobre a análise das experiências e dos saberes revelados em suas narrativas. A cultura do encontro e do diálogo caracteriza as narrativas, as quais são estratégias férteis para o desenvolvimento profissional, por serem potencializadoras da reflexão sobre a ação.

\section{Referências}

FRANKLIN, C. A. et al. The GAISE Project: developing statistics education guidelines for grades Pre-K12 and College courses. In: BURRIL, G. F. Thinking and reasoning with data and chance. Reston/VA: NCTM, 2007. p. $345-375$.

FREITAS, M. T. M.; FIORENTINI, D. As possibilidades formativas e investigativas da narrativa em educação matemática. Horizontes - Revista do Programa de Pós-Graduação Stricto Sensu em Educação da Universidade São Francisco, Itatiba, SP, v. 25, n. 1, p. 63-71, jan./jun. 2007.

GALVÃO, C. Narrativas em Educação. Ciência \& Educação - Unesp, Bauru, v. 11, n. 2, p. 327-345, maio/ago. 2005.

GARFIELD, J.; GAL, I. Teaching and assessing statistical reasoning. In: STILL, L. (Ed.). Developing Mathematical reasoning in grades K-12: National Council Teachers of Mathematics 1999 (Yearbook). Reston/VA: NCTM, 1999. p. 207-219. 
LEAL, B. Escrever é inscrever-se (na forma de um prefácio). In: LACERDA, M. P. (Org.). A escrita inscrita na formação docente. Rio de Janeiro: Rovelle, 2009. p.11-16.

LOPES, C. E. O conhecimento profissional de professores da Educação Infantil e suas relações com a Estatística e a Probabilide. 2003. 290 f., Tese (Doutorado em Educação) - Faculdade de Educação, Universidade Estadual de Campinas, Campinas/SP, 2003.

LOPES, C. E. Reflexões teórico-metodológicas para a Educação Estatística. In: LOPES, C. E.; CURI, Edda. Pesquisas em Educação Matemática: um encontro entre a teoria e a prática. São Carlos/SP: Pedro \& João Editores, 2008. p. 67-86.

MARCELO GARCÍA, C. Formação de professores: para uma mudança educativa. Lisboa: Porto Editora, 1999.

NACARATO, A. M.; PASSEGGI, M. C. Narrativas da experiência docente em matemática de professorasalunas em um curso de pedagogia. In: SIMPÓSIO INTERNACIONAL DE ESTUDOS DE GÊNEROS TEXTUAIS - SIGET, 6., 16 a 19 de agosto de 2011, Natal. Anais... Natal, 2011. p. 1-14. Disponível em: $<$ http://www.cchla.ufrn.br/visiget/pgs/pt/anais/Artigos/ir\%20M.\%20Nacarato\%20(USF)\%20e\%20Maria\% 20da\%20Concei\%C3\%A7\%C3\%A3o\%20Passeggi\%20(UFRN).pdf>. Acesso em: 25 jul. 2013.

PÉREZ, C. L. V. Histórias de escola e narrativas de professores: a experiência do GEPEMC. Memória e cotidiano. In: SOUZA, E. C. de. Autobiografias, histórias de vida e formação:pesquisa e ensino. Porto Alegre: EDIPUCRS, 2006. p.177-188.

PFANNKUCH, M.; BEN-ZVI, D. Developing teachers' statistical thinking. In: BATANERO, C.; BURRILL, G.; READING, C. (Ed.). Teaching Statistics in School Mathematics-Challenges for Teaching and Teacher Education: A Joint ICMI/IASE Study. New York: Springer, 2011. p. 323-333.

REIS, P. R. dos. As narrativas na formação de professores e na investigação em Educação. Nuances: Estudos sobre Educação - Revista Eletrônica do Programa de Pós-Graduação em Educação - Unesp, Presidente Prudente, v. 15, n. 16, p. 17-34, jan./dez. 2008.

SANTOS, S. A narrativa como estratégia de formação e de reflexão sobre a prática docente. Revista Teoria e Prática da Educação - Departamento de Teoria e Prática da Educação, vinculada ao Programa de Pós-Graduação em Educação do Centro de Ciências Humanas, Letras e Artes da Universidade Estadual de Maringá, Maringá, v. 11, n. 2, p. 207-217, maio/ago. 2008. Disponível em:

<http://www.dtp.uem.br/rtpe/volumes/v11n2/sumario.htm>. Acesso em: 27 jul. 2013.

Submetido em Agosto de 2013. Aprovado em Janeiro de 2014. 